\title{
Acceptance Ratio Analysis: An Early Fault Indicator for Grid- Connected Photovoltaic System
}

\author{
Fatin Azirah Mohd. Shukor ${ }^{a}$, Hedzlin Zainuddin ${ }^{\mathrm{a}, \mathrm{b}, *}$, Nurmalessa Muhammad ${ }^{\mathrm{a}, \mathrm{b}}$, \\ Farah Liyana Muhammad Khir ${ }^{\mathrm{a}, \mathrm{b}}$ \\ ${ }^{a}$ Faculty of Applied Sciences, Universiti Teknologi MARA, Shah Alam, Selangor, 40450, Malaysia \\ ${ }^{b}$ SPECTRA Research Interest Group, Universiti Teknologi MARA, Shah Alam, Selangor, 40450, Malaysia \\ Corresponding author: *hedzl506@uitm.edu.my
}

\begin{abstract}
This paper presents the Acceptance Ratio (AR) analysis for three different grid-connected photovoltaic (GCPV) systems working under the Malaysia tropical climate. $\mathrm{AR}$ is a ratio between actual $\mathrm{AC}$ power, $\mathrm{P}_{\mathrm{AC} \text { actual, }}$ and predicted $\mathrm{AC}$ power, $\mathrm{P}_{\mathrm{AC} \text { predicted }}$. According to Malaysian Standard MS2692:2020, the AR value must $\geq 0.9$ to classify as accepted in testing and commissioning test. In contrast, a rate $<0.9$ indicates a non-accepted GCPV system. Historical data of the AC power output, solar irradiance, and module temperature from January 1 to December 31, 2019, were used for the analysis. The analysis procedure was carried out using Matlab and Microsoft Excel software. The analysis covers the AC power analysis and the AR analysis based on the threshold of 0.9 . The plotted monthly AC power graph shows that all systems have lower than $15 \%$ differences between actual and predicted AC power. On the AR analysis, System 1 was found to show early fault indicator with a monthly cumulative percentage of AR $<0.9$ ranges from $34 \%$ to 71 $\%$, meanwhile System 2 and System 3 have a lower cumulative percentage of AR $<0.9$ ranges from $5 \%$ to $19 \%$. This result suggested that only System 2 and 3 are fault-free GCPV systems and working in good condition. The outcome of this study has succeeded in providing preliminary AR analysis results for three GCPV systems located in Malaysia. This study would help to evaluate AR threshold reliability to indicate an early fault of a GCPV system.
\end{abstract}

Keywords - Acceptance ratio; photovoltaic; grid-connected; AC power; AR threshold.

Manuscript received 22 Jul. 2020; revised 5 Mar. 2021; accepted 11 Apr. 2021. Date of publication 30 Jun. 2021. IJASEIT is licensed under a Creative Commons Attribution-Share Alike 4.0 International License.

\section{INTRODUCTION}

The depletion of fossil fuels has drawn attention towards renewable energy sources such as solar photovoltaic (PV) where the sunlight is directly converted into electricity [1], [2]. PV system can be categorized into three types; namely gridconnected photovoltaic (GCPV) system, stand-alone photovoltaic (SAPV) system, and hybrid PV system [3]-[4]. However, over the years, the installed PV system's performance might be reduced due to various losses at the system [5], [6]. In addition, some of the factors are due to faults or abnormalities present in operation [7].

Numerous factors influenced the PV systems' performance, such as design errors, faulty PV modules, aging, faulty assembly of the PV systems, hot spots on PV modules, PV module pollution, PV module partial shading, ambient temperature, changes in sunlight conditions, and many more. Many research studies have analyzed the effects of temperature [8], [9] and other environmental factors [10], [11] on the operation of PV systems. There is also research carried out on partial shading [12] and module pollution [13] on the performance of PV systems. Examples of faulty modules are browning and yellowing, cracks in cells, bubbles in the solar module, hot spots effect by the panel acting as loads, and the defects in the anti-reflective coating [14], [15]. Aging effects might be due to external factors such as overlaying dust, dirt, bird droppings, surrounding vegetation or fence, shading, or strong winds, which might affect the modules [16].

Faults must be identified to avoid energy losses and fire hazards, which would prolong the lifetime of the PV system and hence can reduce the maintenance cost [4]. Various studies were conducted on fault detection which include thermal infrared method [17], [18], artificial intelligent technique [19], [20], time-domain reflectometry method [21], [22], and mathematical model approach [23], [24]. There was also research on the analysis of PV string failure and the PV systems' health monitoring[13], [25]. To date, there is still less scientific research using the mathematical model 
approach on the fault detection of PV systems [26]. Hence, this research has the potential to highlight the studies on analyzing PV systems analytically.

In Malaysia, it is commonly seen that studies on fault detections are based on the mathematical model approach includes power output analysis. This power analysis compared actual AC power and predicted AC power, leading to the Acceptance Ratio (AR) value as a specific threshold value [7]. However, AR analysis in Malaysia has not been widely studied in reporting early fault detection [7].

Acceptance Ratio (AR) is also known as the indicator of PV systems output power. This indicator is significant to indicate the condition of the PV systems. In Malaysia, the Sustainable Energy Development Authority (SEDA) has declared that the guidelines procedure for the Testing and Commissioning of Grid-Connected Photovoltaic Systems acceptable value for AR is greater than or equal to 0.9 [27]. Thus, this paper aims to evaluate the reliability of 0.9 as the AR threshold for indicating the early fault of a GCPV system in Malaysia. An AR analysis was conducted on several real operating GCPV systems in Malaysia to achieve the aim.

\section{MATERIAL AND Method}

\section{A. System Description}

There are three GCPV systems involved in this study. Two sites are located in Negeri Sembilan $\left(2.5905^{\circ} \mathrm{N}, 102.0930^{\circ} \mathrm{E}\right.$ and $\left.2.7259^{\circ} \mathrm{N}, 101.9378^{\circ} \mathrm{E}\right)$ and another site situated in Terengganu $\left(5.2077^{\circ} \mathrm{N}, 103.2049^{\circ} \mathrm{E}\right)$. It is best to note that all the sites are situated on the East side of Malaysia.

All systems at the sites stated use polycrystalline modules installed on the rooftop with an inclination angle of $30^{\circ}$ and PV array power of $10 \mathrm{~kW}_{\mathrm{p}}$. The details of the selected systems are described in Table I.

TABLE I

PV MODULE AND INVERTER DESCRIPTION

\begin{tabular}{llcc}
\hline Description & System 1 & System 2 & System 3 \\
\hline Location & $\begin{array}{c}\text { Negeri } \\
\text { Sembilan }\end{array}$ & $\begin{array}{c}\text { Negeri } \\
\text { Sembilan }\end{array}$ & Terengganu \\
$\begin{array}{l}\text { Type of PV } \\
\text { module }\end{array}$ & PT-P660250W & \\
$\begin{array}{l}\text { Maximum Peak } \\
\text { Power ( }\end{array}$ p) & $250 \mathrm{~W}$ \\
Module & & \\
Efficiency (\%) & 15.37 \\
Type of Inverter & BLUEPLANET 9.0 TL3 \\
Maximum & 98.30 \\
Efficiency (\%) & & \\
\hline
\end{tabular}

The weather monitoring station and inverter were connected to the data loggers that record AC power output, solar irradiance, cell temperature or module temperature, ambient temperature, and wind speed. Each data was recorded in every 5 minutes interval per day. In addition, the historical data of AC power output, solar irradiance, and module temperature covering from January 1-December 31, 2019, were extracted for further analysis.

\section{B. AC power analysis $\left(P_{A C_{-} \text {actual }}\right.$ and $\left.P_{A C \text { predicted }}\right)$}

This section presents the analysis between actual and predicted $\mathrm{AC}$ power. A flow chart of $\mathrm{AC}$ power analysis is presented in Fig. 1 below:

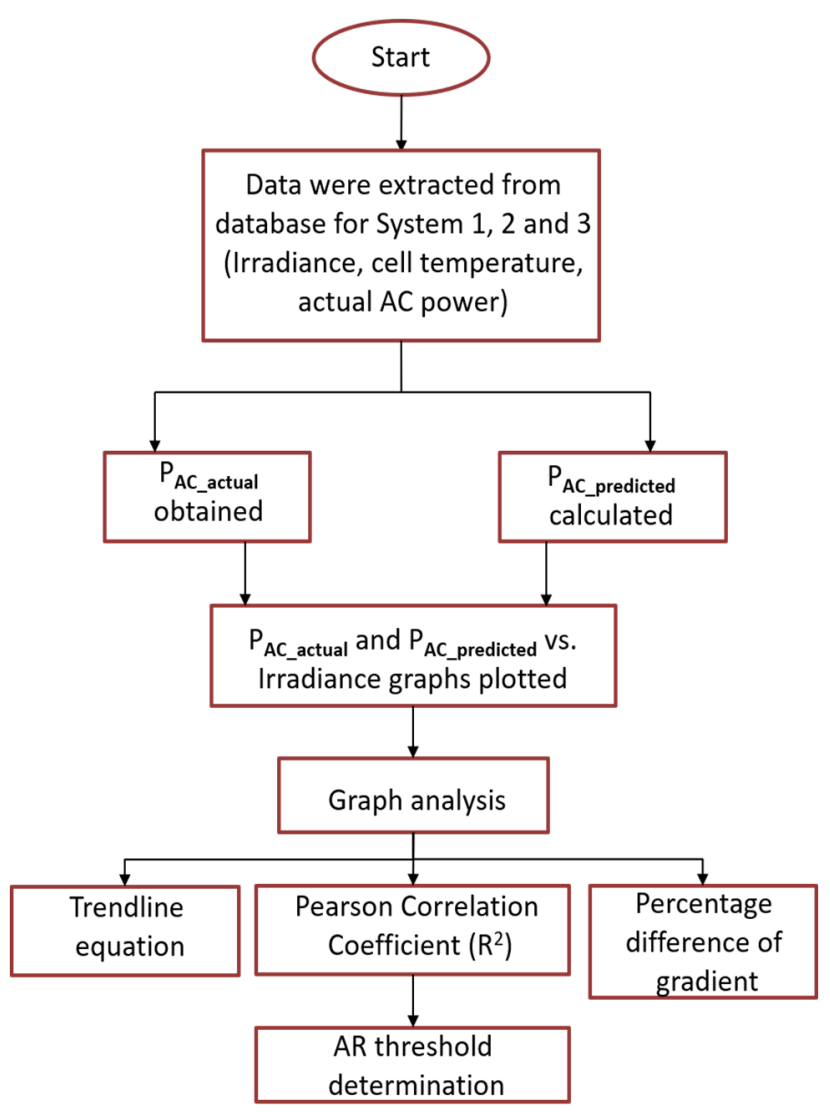

Fig. 1 A flowchart for AC power analysis

Based on Fig. 1, the actual AC power was extracted from the data logger; meanwhile, predicted AC power was calculated using the mathematical model. The mathematical model for predicted AC power $\left(P_{A C \text { predicted }}\right)$ is as expressed by [28]-[29]:

$$
P_{A C_{-} \text {predicted }}=P_{\text {modSTC }} \times N_{\text {Total }} \times f_{\text {der }}
$$

Where $P_{\text {modSTC }}$ is the power of PV module at Standard Test Condition, STC $\left(\mathrm{W}_{\mathrm{p}}\right), N_{\text {Total }}$ is the total number of PV modules and $f_{d e r}$ is the derating factor. The $f_{d e r}$ is expressed by [29]:

$$
f_{\text {der }}=f_{g} \times f_{\text {temp }} \times f_{\text {mm }} \times f_{\text {age }} \times f_{\text {dirt }} \times \eta_{\text {cab }} \times \eta_{\text {inV }}
$$

The mathematical sequential steps are shown as below:

Step 1: Determine peak sun factor, $f_{g}$

$$
f_{g}=\frac{G}{1000}
$$

Dividing solar irradiance at the instant time, $\mathrm{G}\left(\mathrm{Wm}^{-2}\right)$ with solar irradiance at STC obtained the peak sun factor.

Step 2: Determine the derating factor due to temperature, $f_{\text {temp }}$.

$$
f_{\text {temp }}=1+\left[\left(\frac{\% \gamma_{p m p}}{100}\right)\left(T_{m}-25\right)\right]
$$

Where $\gamma_{p m p}$ is the temperature coefficient of power $\left(\% /{ }^{\circ} \mathrm{C}\right)$ and $T_{m}$ is the temperature of PV module. 
Step 3: Determination of remaining derating factors as tabulated in Table II:

TABLE II

DETERMINATION OF REMAINING DERATING FACTORS

\begin{tabular}{ll}
\hline Parameters & References \\
\hline Module mismatch, $f_{m m}$ & Module datasheet \\
Aging factor, $f_{\text {age }}$ & $\begin{array}{l}\text { Module datasheet \& Age of PV } \\
\text { system }\end{array}$ \\
Dirt factor, $f_{\text {dirt }}$ & $0.97[30]$ \\
The efficiency of cable, $\eta_{c a b}$ & $0.97[30]$ \\
The efficiency of the inverter, & Inverter datasheet \\
$\eta_{\text {inv }}$ & \\
\hline
\end{tabular}

Monthly graphs of $\mathrm{P}_{\mathrm{AC} \_ \text {actual }}$ and $\mathrm{P}_{\mathrm{AC} \_ \text {predicted }}$ were plotted and analyzed. Based on the graph, $\mathrm{P}_{\mathrm{AC} \text { predicted }}$ must lie within $\mathrm{P}_{\mathrm{AC} \text { actual }}$ to show that the system is in good condition. On the other hand, if $\mathrm{P}_{\mathrm{AC} \_ \text {predicted }}$ and $\mathrm{P}_{\mathrm{AC} \text { _actual }}$ are not aligned, and the percentage difference between the two gradients of $\mathrm{P}_{\mathrm{AC} \text { _predicted }}$ and $\mathrm{P}_{\mathrm{AC} \_ \text {actual }}$ is high, the system is considered as showing an early fault symptom [7].

These graphs were then analyzed by determining the trendline equation, Pearson correlation coefficient $\left(\mathrm{R}^{2}\right)$, and gradient difference. This analysis was the preceding step before determining the AR threshold, as discussed in the following section (Section C).

\section{Acceptance Ratio Analysis}

This section presents the AR analysis flow chart as shown in Fig. 2. The AR was calculated based on the ratio of $P_{A C}$ actual

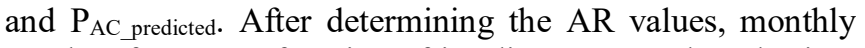
graphs of $A R$ as a function of irradiance were plotted. First, the AR threshold of 0.9 was identified in each monthly graph. Next, the monthly cumulative percentage of AR values greater than or equal to 0.9 and less than 0.9 were calculated, respectively. The AR monthly cumulative percentage based on three GCPV system's AR thresholds was presented in a bar chart for comparison.

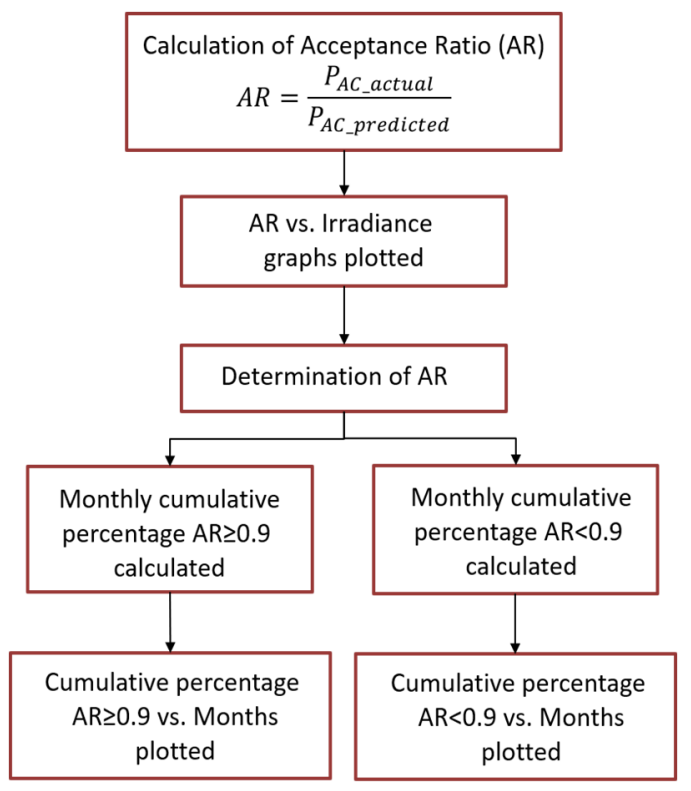

Fig. 2 A flowchart of AR analysis

\section{RESULT AND DISCUSSION}

The result and analysis are divided into two sections: AC power analysis and AR threshold. All analysis was carried out using MATLAB software and Microsoft Excel.

\section{A. AC Power Graphs}

For this study, the actual AC power output data for three selected GCPV systems were based on the data obtained in 2019. The data used were recorded every 5 minutes. These data were then analyzed using MATLAB software. Fig. 3 until Fig. 38 shows the actual (red color) plot and predicted (blue color) AC power of each system.

\section{1) AC power graphs for System 1:}

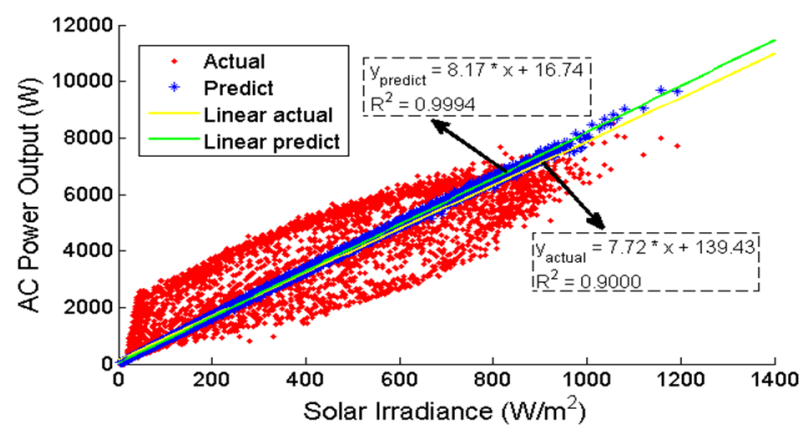

Fig. 3 AC power output versus solar irradiance in January 2019

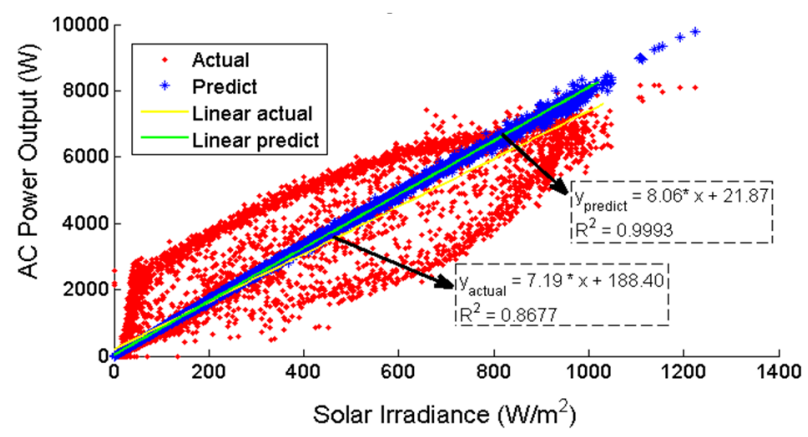

Fig. 4 AC power output versus solar irradiance in February 2019

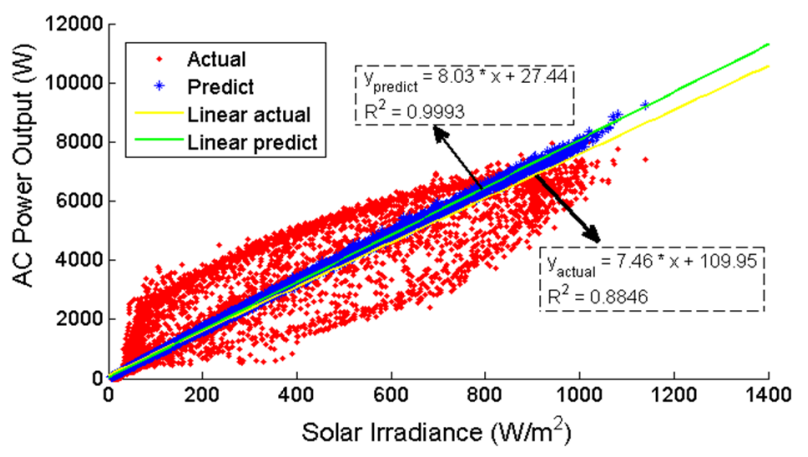

Fig. 5 AC power output versus solar irradiance in March 2019 


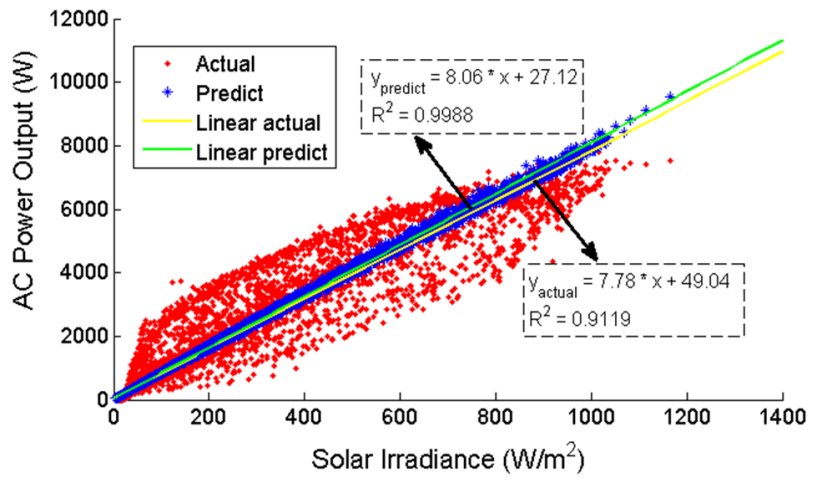

Fig. 6 AC power output versus solar irradiance in April 2019

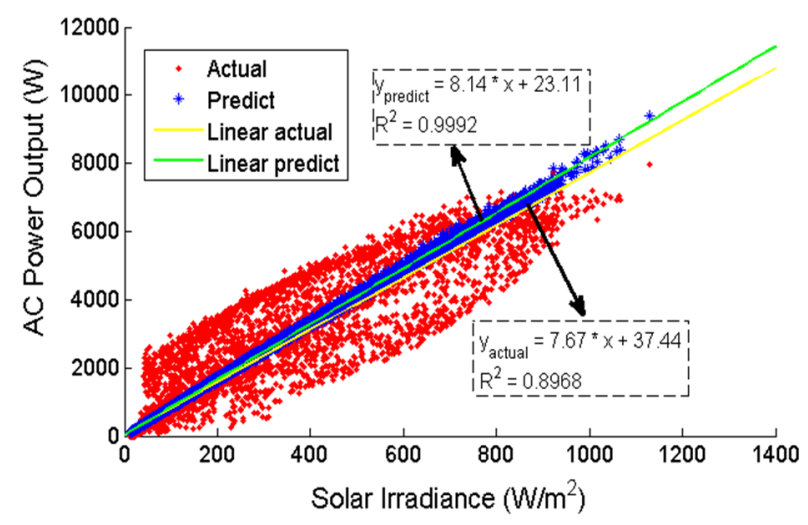

Fig. 7 AC power output versus solar irradiance in May 2019

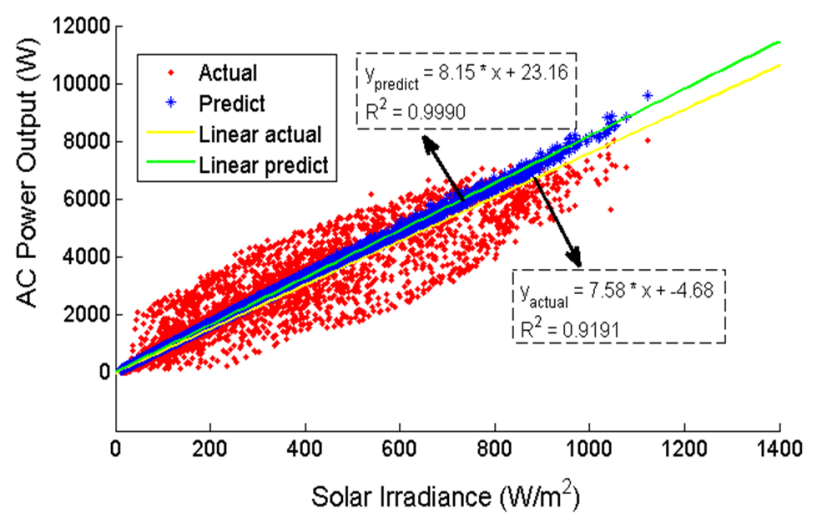

Fig. 8 AC power output versus solar irradiance in June 2019

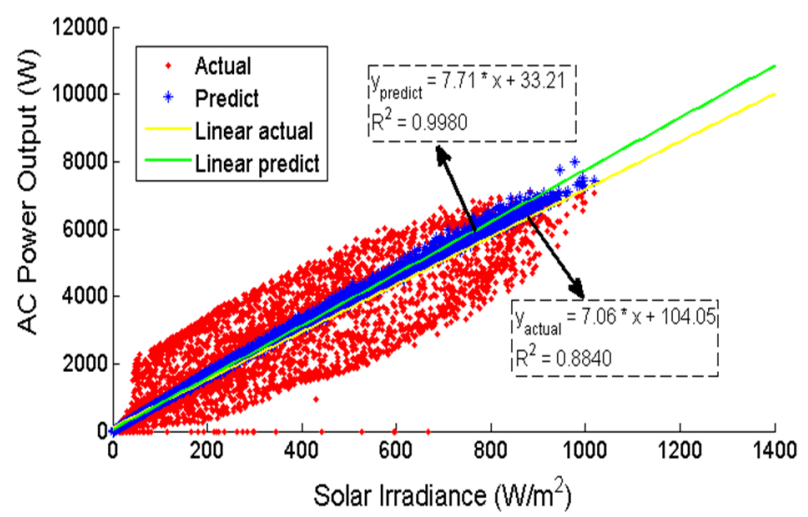

Fig. 9 AC power output versus solar irradiance in July 2019

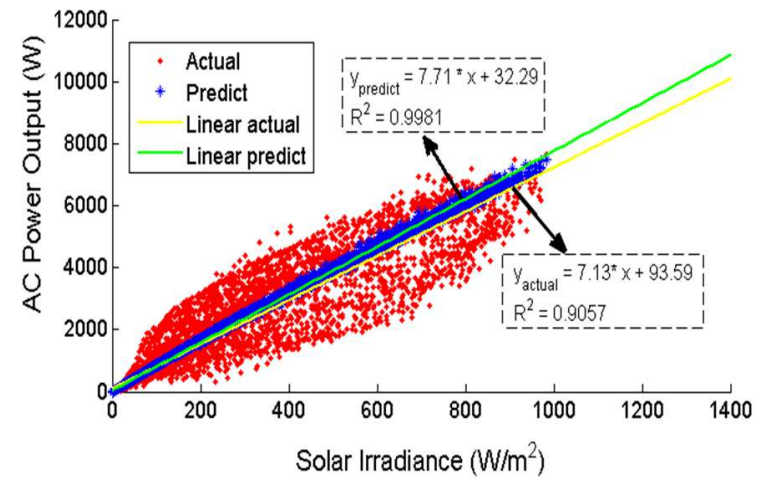

Fig. 10 AC power output versus solar irradiance in August 2019

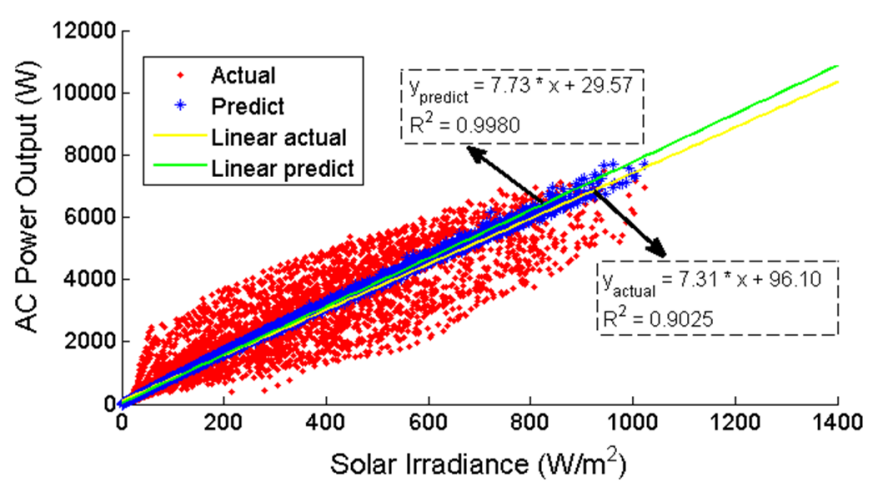

Fig. 11 AC power output versus solar irradiance in September 2019

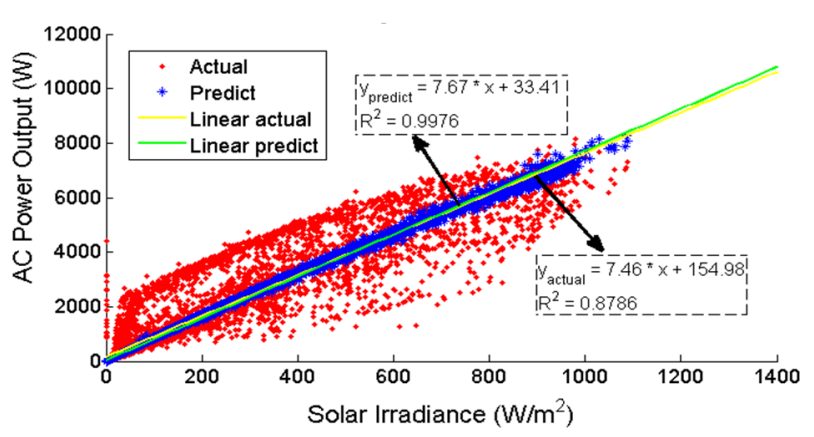

Fig. 12 AC power output versus solar irradiance in October 2019

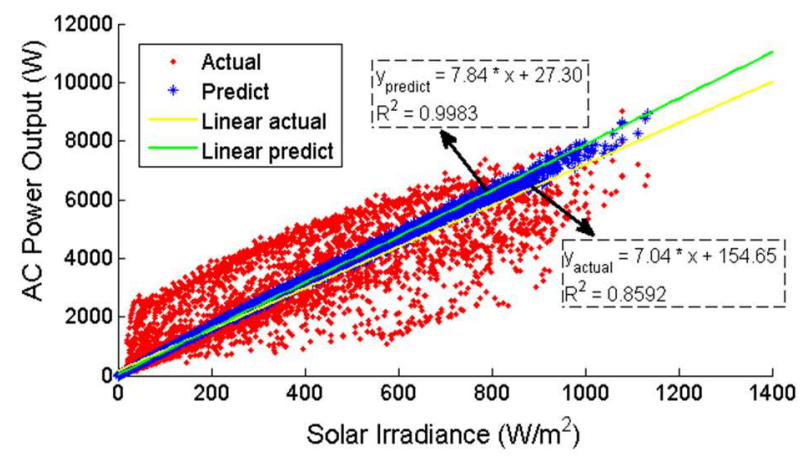

Fig. 13 AC power output versus solar irradiance in November 2019 


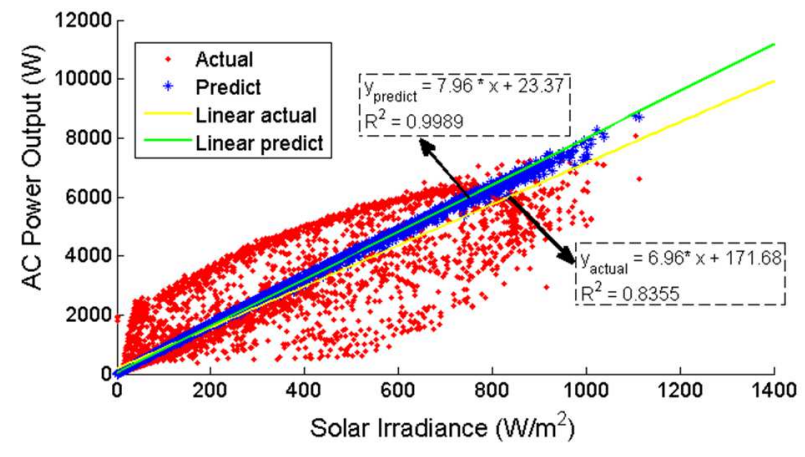

Fig. 14 AC power output versus solar irradiance in December 2019

Based on Fig. 3 until Fig. 14, System 1 shows interesting behavior. Notably, actual AC power's value starts to deviate from the prediction when the irradiance reached about 80 $\mathrm{Wm}^{-2}$. The irradiance of $80 \mathrm{Wm}^{-2}$ was identified as Thermal Equilibrium Point (TEP) between the PV module temperature and ambient temperature in a PV module temperature modeling study in Shah Alam, Malaysia [31]. After TEP, the main factor that affecting the PV module temperature is mainly solar irradiance [31]. Due to this reason, the deviation after $80 \mathrm{Wm}^{-2}$ was suspected due to the variation of solar irradiance that was highly affecting the PV module temperature, and consequently, the $\mathrm{AC}$ power output of the PV system. Another possible suggestion is that the PV array with dual-orientation and solar irradiance sensor placement may result in the deviation behavior. The solar irradiance sensor was placed at only one side of the PV array orientations for the systems with dual orientation. Thus, it reflects the different paths of the actual $\mathrm{AC}$ power trend line compared to the predicted $\mathrm{AC}$ power trend line. The actual $\mathrm{AC}$ power data plot above the trend line is suspected originated from power output before solar noon, and the actual AC power data plot below the trend line is suspected originated from the power output after solar noon.

For System 2 (refer to Fig. 15 until Fig. 26), it can be observed that the actual AC power is aligned with predicted $\mathrm{AC}$ power as irradiance increases for the whole year. However, in May and September 2019, some of the AC power values were recorded as zero. It is suggested that there is a technical problem in the system that affects the inverter.

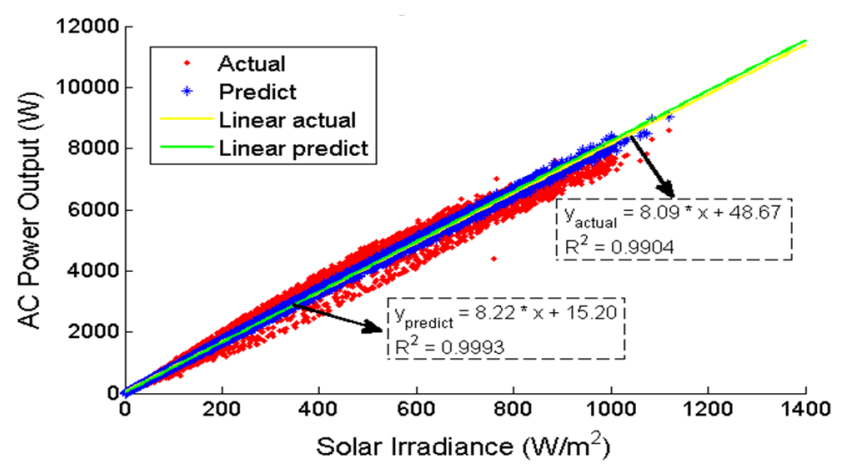

Fig. 15 AC power output versus solar irradiance in January 2019

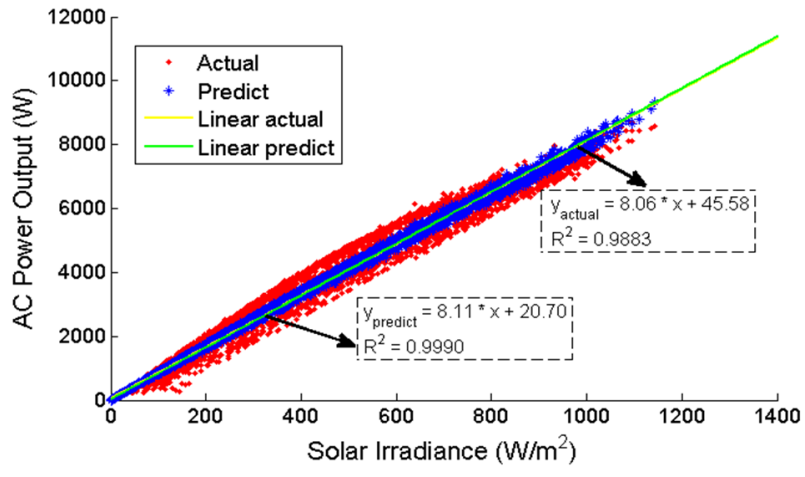

Fig. 16 AC power output versus solar irradiance in February 2019

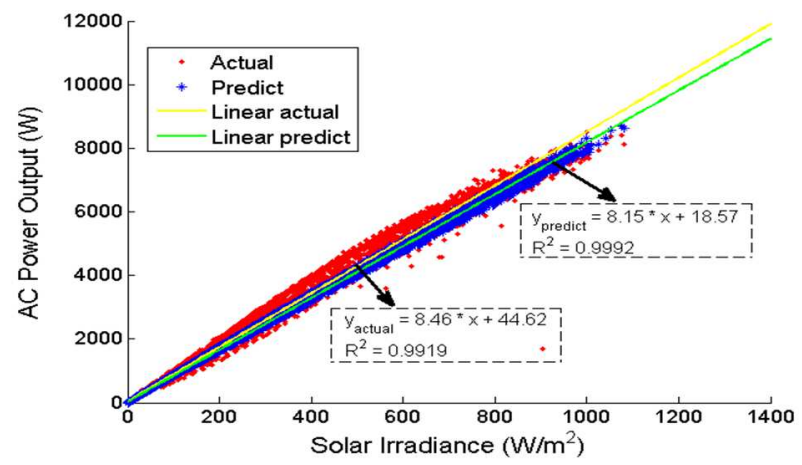

Fig. 17 AC power output versus solar irradiance in March 2019

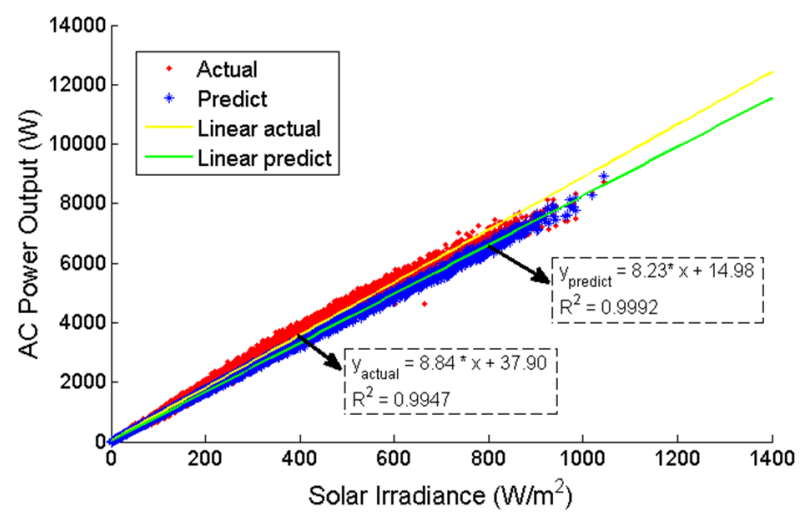

Fig. 18 AC power output versus solar irradiance in April 2019

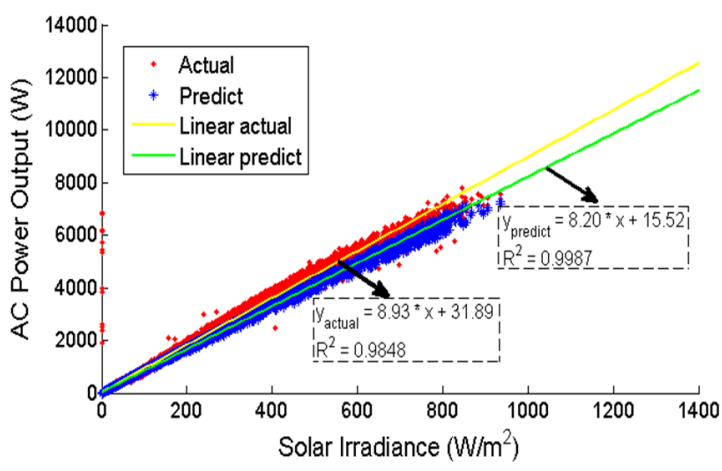

Fig. 19 AC power output versus solar irradiance in May 2019 


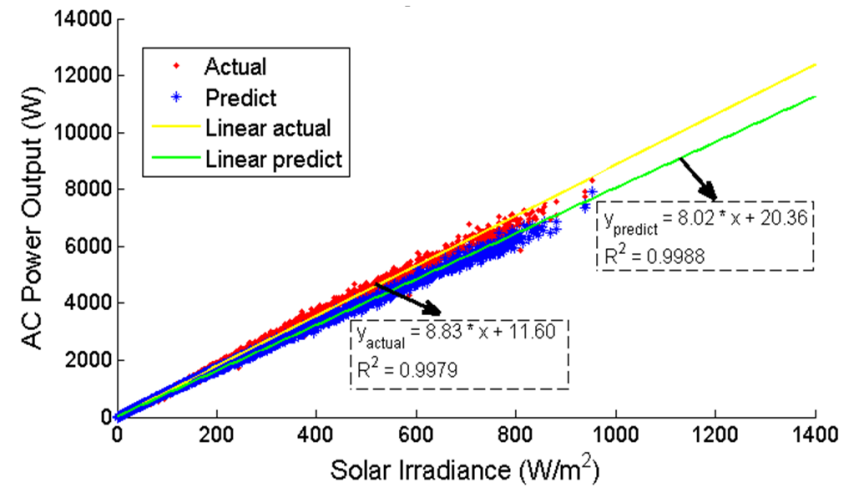

Fig. 20 AC power output versus solar irradiance in June 2019

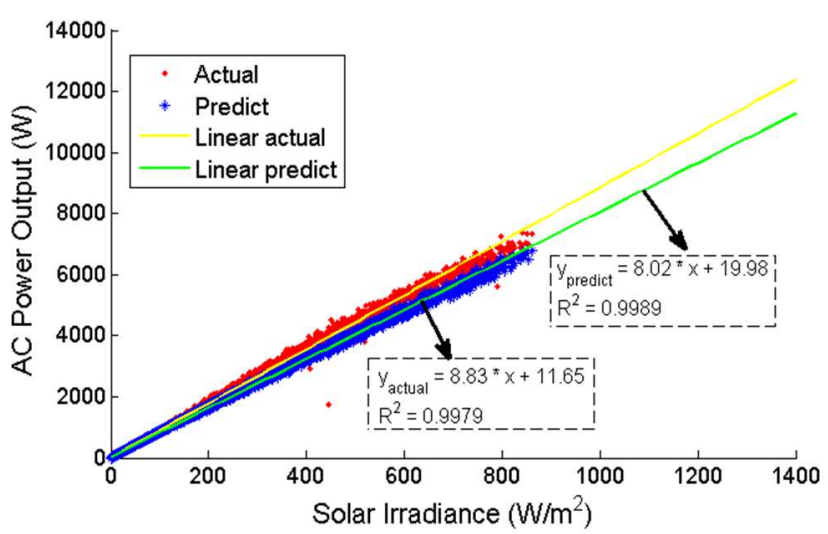

Fig. 21 AC power output versus solar irradiance in July 2019

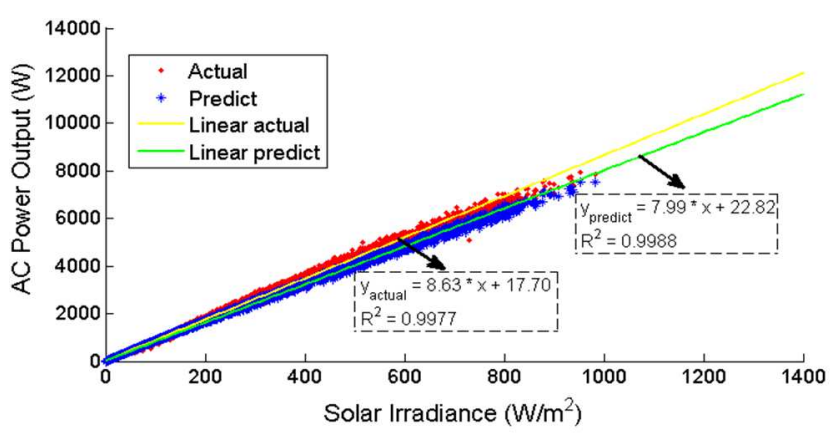

Fig. 22 AC power output versus solar irradiance in August 2019

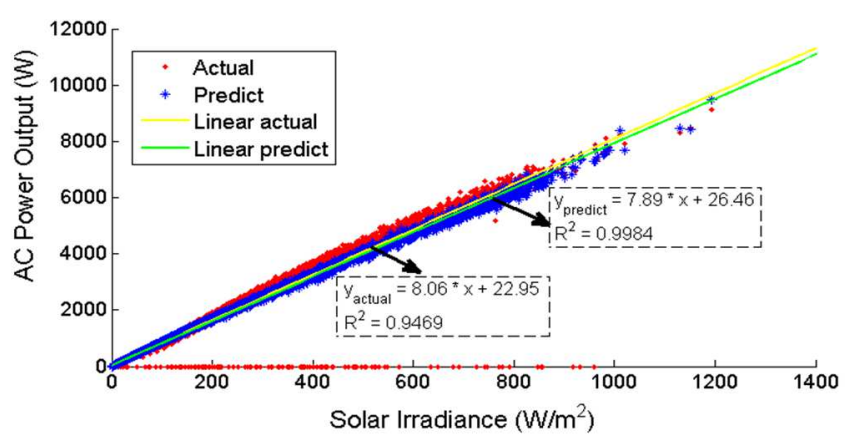

Fig. 23 AC power output versus solar irradiance in September 2019

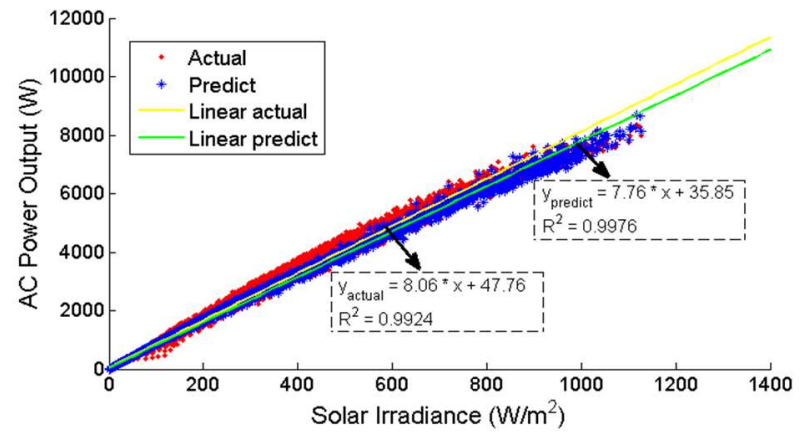

Fig. 24 AC power output versus solar irradiance in October 2019

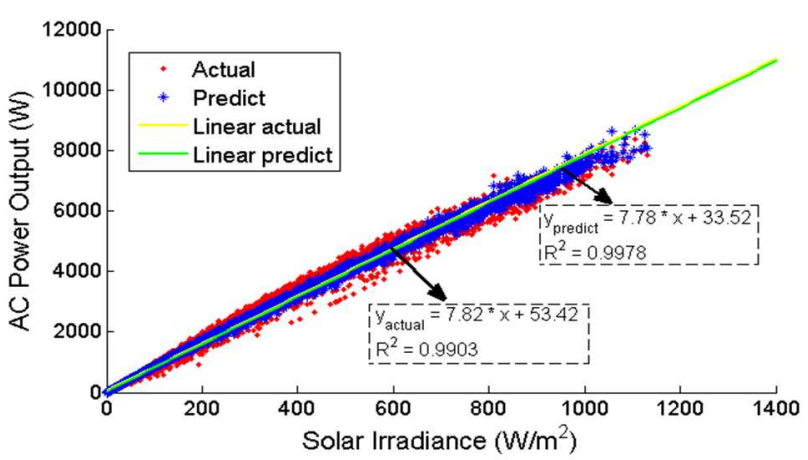

Fig. 25 AC power output versus solar irradiance in November 2019

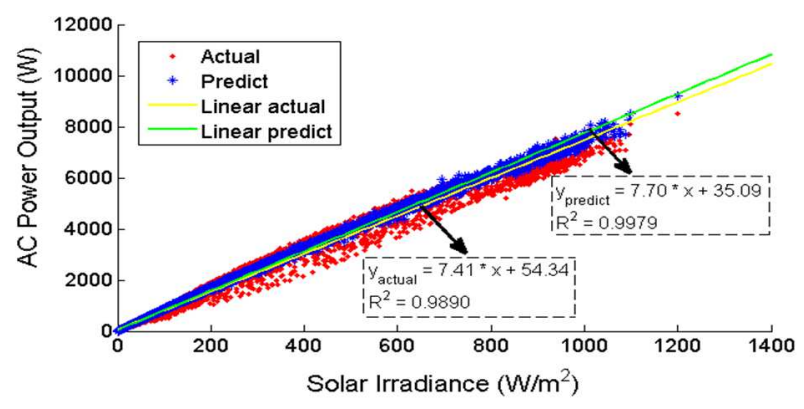

Fig. 26 AC power output versus solar irradiance in December 2019

2) AC power graphs for System 2

Finally, for System 3 (refer to Fig. 27 until Fig. 38), the actual $\mathrm{AC}$ power graphs are quite aligned, but some of the $\mathrm{P}_{\mathrm{AC} \text { actual }}$ were observed to fluctuate from low and high irradiance prediction. This might be due to the $\mathrm{P}_{\mathrm{AC}}$ actual data recorded inside the cloud server storing not synchronized with the actual measurement generated by the inverter [24].

3) AC power graphs for System 3

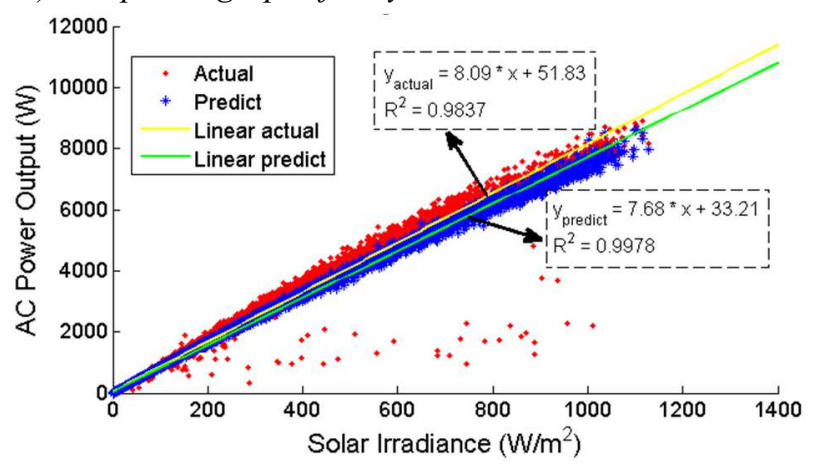

Fig. 27 AC power output versus solar irradiance in January 2019 


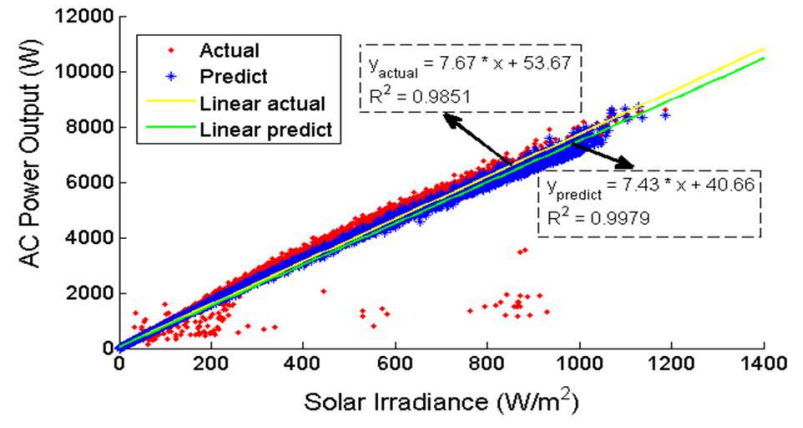

Fig. 28 AC power output versus solar irradiance in February 2019

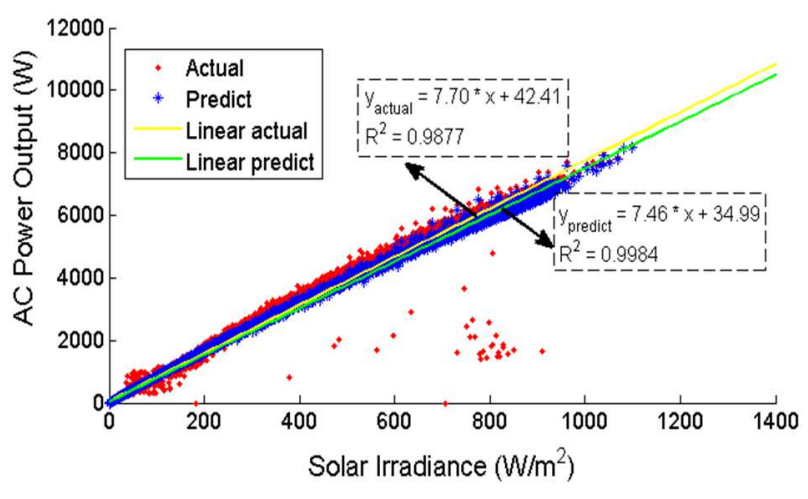

Fig. 29 AC power output versus solar irradiance in March 2019

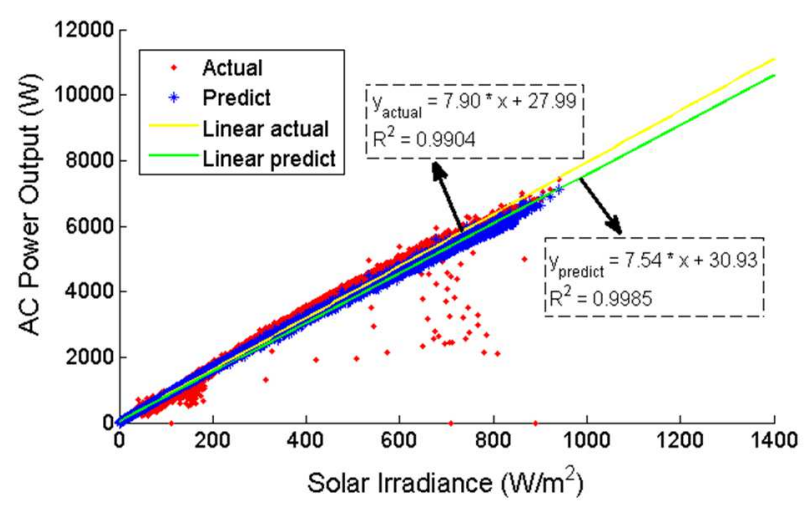

Fig. 30 AC power output versus solar irradiance in April 2019

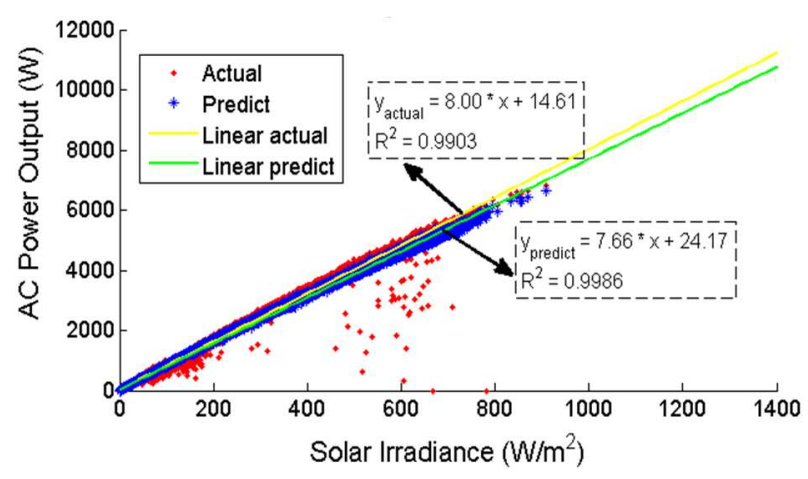

Fig. 31 AC power output versus solar irradiance in May 2019

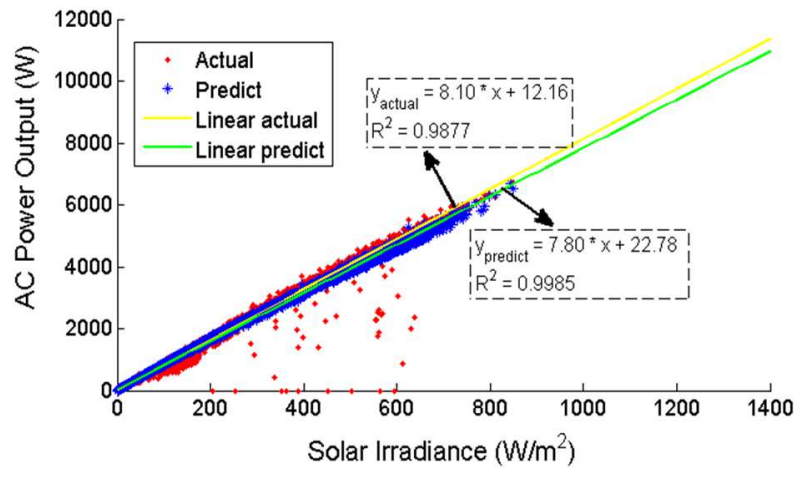

Fig. 32 AC power output versus solar irradiance in June 2019

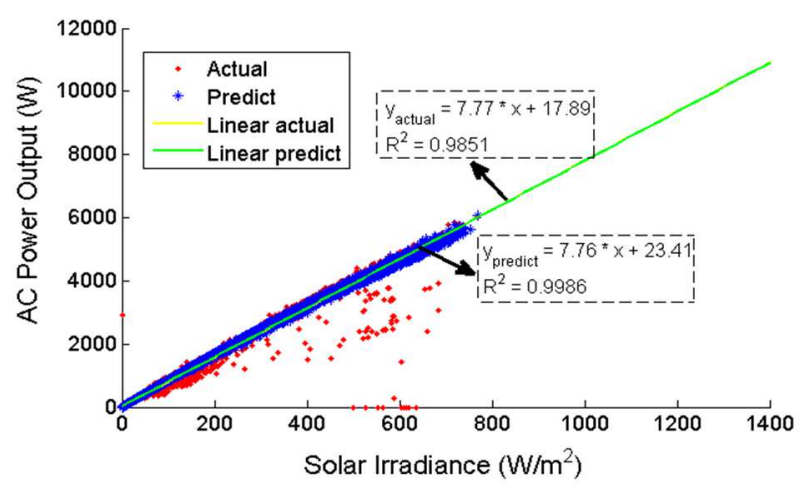

Fig. 33 AC power output versus solar irradiance in July 2019

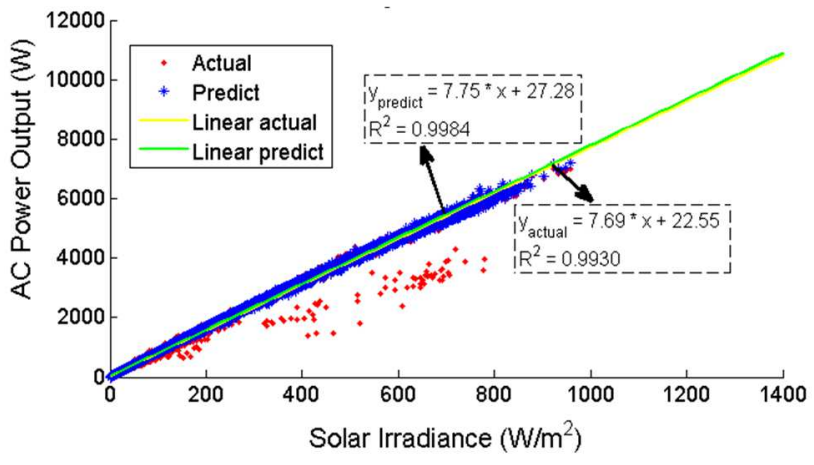

Fig. 34 AC power output versus solar irradiance in August 2019

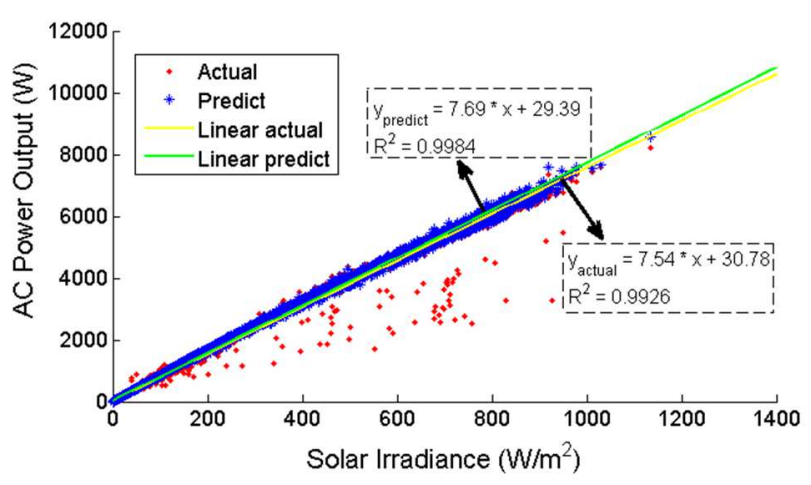

Fig. 35 AC power output versus solar irradiance in September 2019 


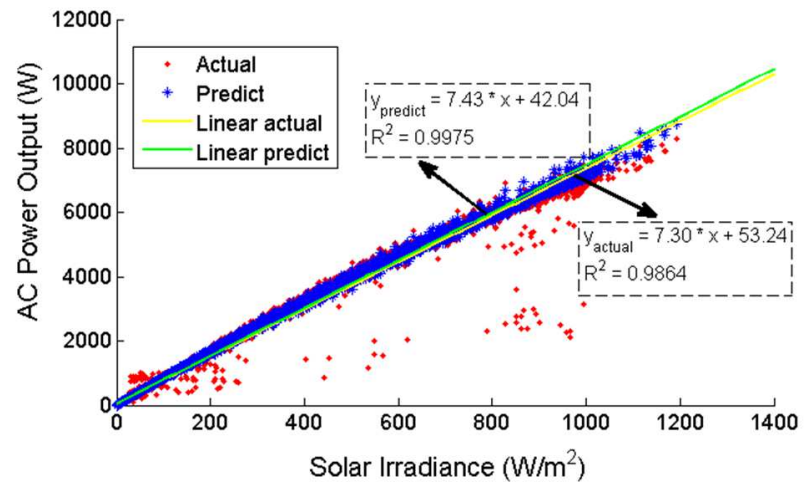

Fig. 36 AC power output versus solar irradiance in October 2019

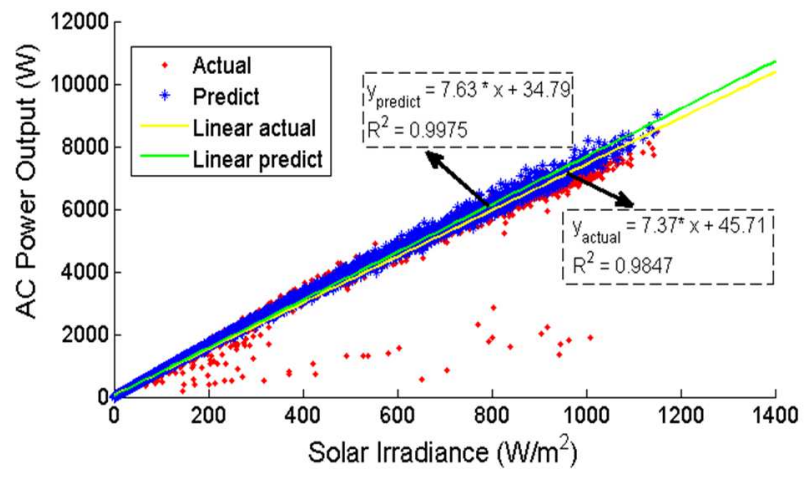

Fig. 37 AC power output versus solar irradiance in November 2019

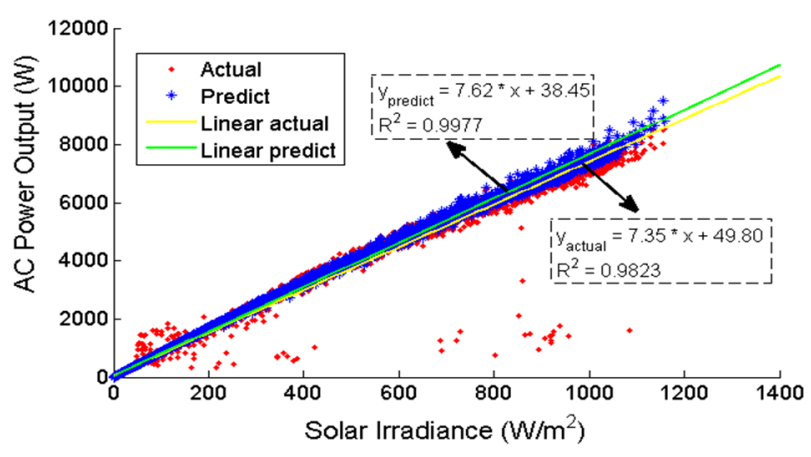

Fig. 38 AC power output versus solar irradiance in December 2019

Percentage difference of gradient between $\mathrm{P}_{\mathrm{AC} \text { actual }}$ and $P_{\text {AC predicted }}$ (each month in the Year 2019) were calculated for Systems 1, 2, and 3. The results were tabulated as in Table III.

TABLE III

Percentage DifFERENCE OF AC POWER GRAPH GRADIENT For ALL SYSTEMS

\begin{tabular}{lccc}
\hline \multirow{2}{*}{ Months } & \multicolumn{3}{c}{ Percentage Difference of Gradient (\%) } \\
& System 1 & System 2 & System 3 \\
\hline Jan & 5.84 & 1.57 & 5.14 \\
Feb & 12.23 & 0.56 & 3.13 \\
Mar & 7.64 & 3.68 & 3.13 \\
Apr & 3.61 & 6.82 & 4.61 \\
May & 6.11 & 8.21 & 4.22 \\
Jun & 7.55 & 9.13 & 3.64 \\
Jul & 9.14 & 9.18 & 0.12 \\
Aug & 8.24 & 7.41 & 0.87 \\
Sep & 5.73 & 2.04 & 1.94 \\
Oct & 2.87 & 3.79 & 1.76 \\
Nov & 11.33 & 0.65 & 3.43 \\
Dec & 14.33 & 3.93 & 3.70 \\
Average & $\mathbf{7 . 8 9}$ & $\mathbf{4 . 7 5}$ & $\mathbf{2 . 9 8}$ \\
\hline
\end{tabular}

The average percentage difference of gradient (based on Table III) indicates that System 1 showed the highest percentage difference of $7.89 \%$ compared to System 2 and 3, $4.75 \%$ and $2.98 \%$, respectively. Furthermore, System 1 exhibited the highest monthly percentage difference of $14.33 \%$. These results suggest that System 2 and 3 are possibly working in good condition. Nevertheless, further investigation needs to be performed for System 1 to evaluate whether it works in good condition or vice versa.

\section{B. AR threshold}

The AR values calculated for 2019 were plotted. The 'dashed line' in blue color represents the AR threshold of 0.9 (as being standardized by SEDA) in the acceptance test, and the commissioning procedures of the GCPV system was included in the graph as a reference. Fig. 39, 40, and 41 shows the plot of AR analysis of the sites in March 2019. The month of March is chosen because it is the month that experiences the Equinox phenomenon in Malaysia, and solar irradiation is expected to be higher than the rest of the months.

Fig. 39 that represents System 1 shows that AR values scatter between zero to 1.6. The apparent scattering is observed when the irradiance is less than $400 \mathrm{Wm}^{-2}$. Nevertheless, Fig. 40, which represents System 2, shows the high $\mathrm{AR}$ values concentration $\geq 0.9$. A similar behavior was also observed in System 3 (represented by Fig. 41).

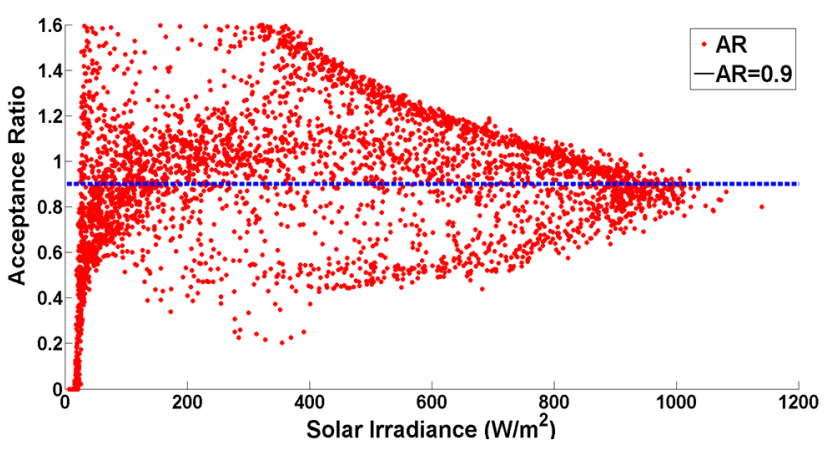

Fig. 39 Acceptance Ratio versus solar irradiance for System 1

Comparatively, System 1 shows different behavior in the AR plot compared to System 2 and 3. Since the AR values were deduced from the AC power analysis, it is suggested that the different behavior in System 1 may occur due to the dualorientation and the solar irradiation sensor placement. Based on these results, it is suggested that further investigation of the early fault symptoms for a dual-orientation system must be conducted to understand the system itself.

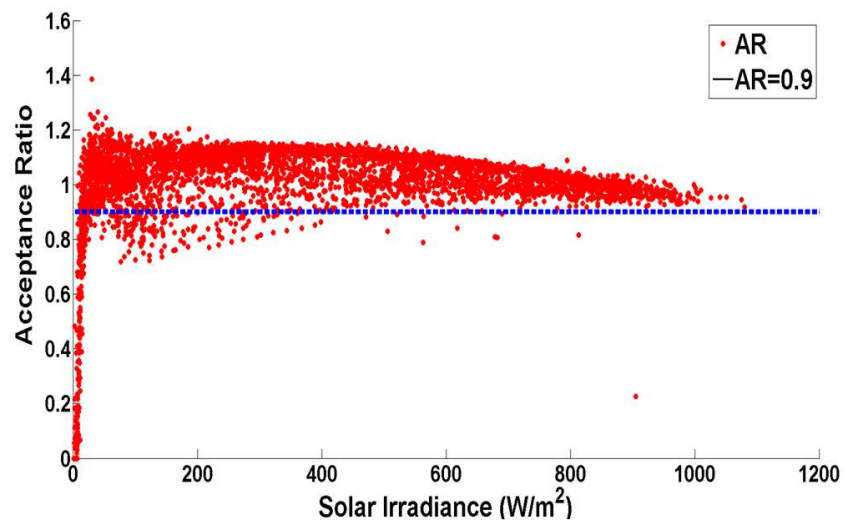

Fig. 40 Acceptance Ratio versus solar irradiance for System 2 


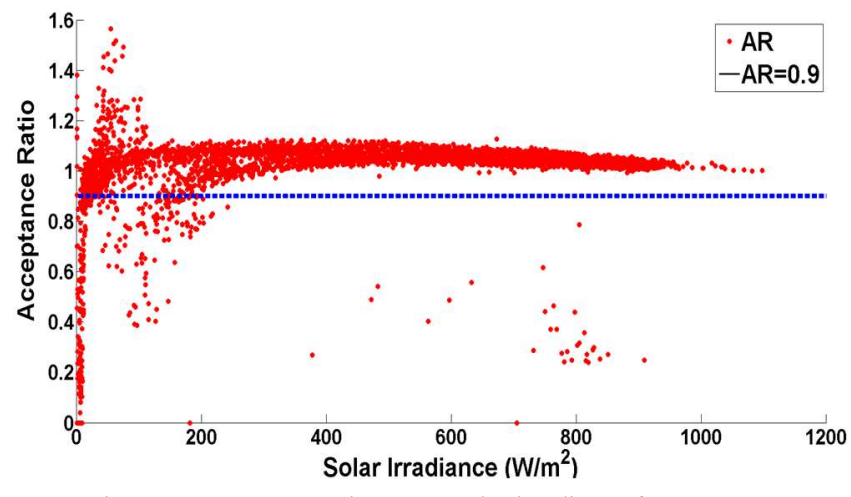

Fig. 41 Acceptance Ratio versus solar irradiance for System 3

Fig. 42 represents the analysis of monthly cumulative percentages $\mathrm{AR} \geq 0.9$ and $\mathrm{AR}<0.9$. The blue color represents the monthly percentages $\mathrm{AR} \geq 0.9$ while the red color represents the monthly percentages of $\mathrm{AR}<0.9$.

System 1 shows the monthly cumulative percentage of $\mathrm{AR}<0.9$ ranges from $34 \%$ to $71 \%$, with an average percentage of $51 \%$. However, five months (i.e., February, March, April, May, and June) recorded approximately $70 \%$ of cumulative percentage of AR $<0.9$.

System 2 and 3 show the percentages of $\mathrm{AR}<0.9$ range from $5 \%$ to $19 \%$, with an average percentage of $11 \%$, which much lower than System 1. However, the maximum percentage of $19 \%$ is in good agreement with the findings found in a study conducted in Shah Alam, Malaysia, for a $5.405 \mathrm{kWp}$ GCPV.

System. The study reported that the cumulative percentage of $\mathrm{AR}<0.9$ must not exceed $31 \%$ to be classified as a faultfree GCPV system [7]. Thus, it can be concluded that System 2 and 3 under investigation are fault-free GCPV systems where their AR percentages are less than $31 \%$.

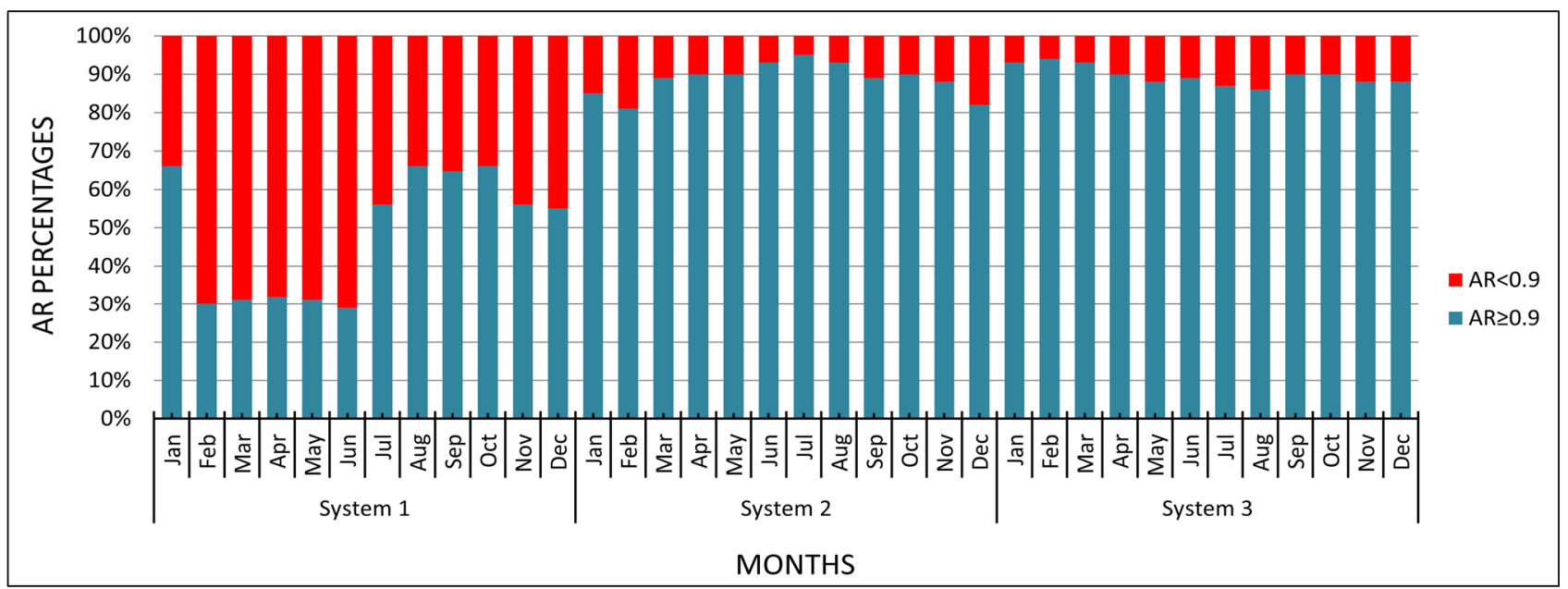

Fig. 42 AR percentages versus months for all selected GCPV systems in 2019

\section{CONCLUSION}

Three GCPV systems located in Malaysia have been investigated based on the AR threshold for early fault detection. From the AR analysis for the whole year of 2019, System 1 was found to have a higher monthly cumulative percentage of $\mathrm{AR}<0.9$ from $34 \%$ to $71 \%$, with five months recorded approximately $70 \%$. On the other hand, System 2 and 3 have a much lower cumulative percentage of AR $<0.9$, $5 \%$ to $19 \%$. These results supported the indication of early fault for System 1. However, further investigation needs to be conducted for System 1 to determine whether differences in PV array orientation and the sensor placement at only one side of the orientation significantly contribute to a higher monthly cumulative percentage of $\quad \mathrm{AR}<0.9$. Besides, more case studies should be conducted, including faulty GCPV systems, to evaluate the AR threshold value's reliability to differentiate between faulty and fault-free GCPV systems.

\section{ACKNOWLEDGMENT}

The authors are grateful to the Green Energy Research Centre (GERC) for the support and guidance throughout the project. This work was funded under research grant 600 IRMI/FRGS 5/3 (446/2019).

\section{REFERENCES}

[1] Z. Othman, S. I. Sulaiman, I. Musirin, A. M. Omar, S. Shaari, and M. Z. Rosselan, "Sizing optimization of Hybrid Stand Alone Photovoltaic system," Int. J. Adv. Sci. Eng. Inf. Technol., vol. 7, no. 6, pp. 19911997, 2017.

[2] M. Ammiche, A. Kouadri, L. M. Halabi, A. Guichi, and S. Mekhilef, "Fault detection in a grid-connected photovoltaic system using adaptive thresholding method," Sol. Energy, vol. 174, no. September, pp. 762-769, 2018.

[3] T. Khatib, A. Yasin, A. A. Mohammad, and I. A. Ibrahim, "On the effectiveness of optimally sizing an inverter in a grid-connected photovoltaic power system," 14th Int. Conf. Smart Cities Improv. Qual. Life Using ICT IoT, pp. 48-52, 2017.

[4] A. Y. Appiah, X. Zhang, B. B. K. Ayawli, and F. Kyeremeh, "Review and performance evaluation of photovoltaic array fault detection and diagnosis techniques," Int. J. Photoenergy, vol. 2019, 2019.

[5] K. B. Samal and A. Bisoyi, "Investigation of Environmental Effects on the Performance of Solar PV Modules," 2020 Int. Conf. Emerg. Front. Electr. Electron. Technol. ICEFEET 2020, pp. 3-7, 2020.

[6] M. Al-Addous, Z. Dalala, F. Alawneh, and C. B. Class, "Modeling and quantifying dust accumulation impact on PV module performance," Sol. Energy, vol. 194, no. October, pp. 86-102, 2019.

[7] N. Muhammad, H. Zainuddin, E. Jaaper, and Z. Idrus, "An early fault detection approach in grid-connected photovoltaic (GCPV) system," Indones. J. Electr. Eng. Comput. Sci., vol. 17, no. 2, pp. 671-679, 2019. 
[8] G. Álvarez-Tey, J. A. Clavijo-Blanco, Á. Gil-García, R. JiménezCastañeda, and C. García-López, "Electrical and thermal behaviour of crystalline photovoltaic solar modules in shading conditions," Appl. Sci., vol. 9, no. 15, 2019.

[9] M. Jaszczur, J. Teneta, Q. Hassan, E. Majewska, and R. Hanus, "An Experimental and Numerical Investigation of Photovoltaic Module Temperature Under Varying Environmental Conditions," Heat Transf. Eng., vol. 42, no. 3-4, pp. 354-367, 2021.

[10] S. Lou et al., "Tilted photovoltaic energy outputs in outdoor environments," Sustain., vol. 11, no. 21, 2019.

[11] R. J. Mustafa, M. R. Gomaa, M. Al-Dhaifallah, and H. Rezk, "Environmental impacts on the performance of solar photovoltaic systems," Sustain., vol. 12, no. 2, pp. 1-17, 2020.

[12] A. M. Humada, M. Hojabri, M. B. Mohamed, M. H. Bin Sulaiman, and T. H. Dakheel, "A proposed method of photovoltaic solar array configuration under different partial shadow conditions," Adv. Mater. Res., vol. 983, pp. 307-311, 2014.

[13] M. Jaszczur et al., "The field experiments and model of the natural dust deposition effects on photovoltaic module efficiency," Environ. Sci. Pollut. Res., vol. 26, no. 9, pp. 8402-8417, 2019.

[14] F. Ancuta and C. Cepisca, "Fault analysis possibilities for PV panels," Proc. 2011 3rd Int. Youth Conf. Energ., no. September 2011.

[15] M. A. Munoz, M. C. Alonso-García, N. Vela, and F. Chenlo, "Early degradation of silicon PV modules and guaranty conditions," Sol. Energy, vol. 85, no. 9, pp. 2264-2274, 2011.

[16] E. Kaplani, "Detection of Degradation Effects in Field-Aged c-Si Solar Cells through IR Thermography and Digital Image Processing," Int. J. Photoenergy, vol. 2012, pp. 1-11, 2012.

[17] S. W. Lee, K. E. An, B. D. Jeon, K. Y. Cho, S. J. Lee, and D. Seo, "Detecting faulty solar panels based on thermal image processing," 2018 IEEE Int. Conf. Consum. Electron. ICCE 2018, vol. 2018-Janua, pp. 1-2, 2018.

[18] D. Kim, J. Youn, and C. Kim, "Automatic fault recognition of photovoltaic modules based on statistical analysis of UAV thermography," Int. Arch. Photogramm. Remote Sens. Spat. Inf. Sci. ISPRS Arch., vol. 42, no. 2W6, pp. 179-182, 2017.

[19] C. Kara Mostefa Khelil, B. Amrouche, A. soufiane Benyoucef, K Kara, and A. Chouder, "New Intelligent Fault Diagnosis (IFD) approach for grid-connected photovoltaic systems," Energy, vol. 211, pp. 1-18, 2020.

[20] Z. Huang, Z. Wang, and H. Zhang, "Multiple Open-Circuit Fault Diagnosis Based on Multistate Data Processing and Subsection
Fluctuation Analysis for Photovoltaic Inverter," IEEE Trans. Instrum. Meas., vol. 67, no. 3, pp. 516-526, 2018.

[21] S. Roy, M. K. Alam, F. Khan, J. Johnson, and J. Flicker, "An Irradiance-Independent, Robust Ground-Fault Detection Scheme for PV Arrays Based on Spread Spectrum Time-Domain Reflectometry (SSTDR)," IEEE Trans. Power Electron., vol. 33, no. 8, pp. 70467057, 2018.

[22] M. U. Saleh et al., "Detection and Localization of Disconnections in PV Strings Using Spread-Spectrum Time-Domain Reflectometry," IEEE J. Photovoltaics, vol. 10, no. 1, pp. 236-242, 2020

[23] T. Pei and X. Hao, "A fault detection method for photovoltaic systems based on voltage and current observation and evaluation," Energies, vol. 12 , no. 9, 2019.

[24] R. Platon, J. Martel, N. Woodruff, and T. Y. Chau, "Online Fault Detection in PV Systems," IEEE Trans. Sustain. Energy, vol. 6, no. 4, pp. 1200-1207, 2015.

[25] N. Muhammad, N. Z. Zakaria, S. Shaari, and A. M. Omar, "Fault Detection Approach in Photovoltaic System Using Mathematical Method Diagnosis Fault Detection Approach In Photovoltaic System Using Mathematical Method Diagnosis," J. Fundam. Appl. Sci., no. March 2018.

[26] M. T. Sarniak, "Research of the impact of the nominal power ratio and environmental conditions on the efficiency of the photovoltaic system: A case study for poland in central Europe," Sustain., vol. 12, no. 15, 2020.

[27] I. S. Tests, P. V Plants, C. At, and M. Voltage, "Procedure for the Testing and Commissioning of Grid-Connected Photovoltaic Systems in Malaysia Inverter Site Tests - Pv Plants Connected At Medium Voltage Sustainable Energy Development Authority (Seda ),” 2014.

[28] SEDA, Malaysia Grid-Connected Design Course. Putrajaya,Malaysia: Sustainable Energy Development Authority Malaysia, 2016.

[29] N. Muhammad, N. Z. Zakaria, S. Shaari, and A. M. Omar, "System performance modelling of a grid-connected photovoltaic system in UiTM, Malaysia," Int. J. Adv. Sci. Eng. Inf. Technol., vol. 7, no. 4, pp. 1275-1281, 2017.

[30] B. Marion et al., "Performance parameters for grid-connected PV systems," Conf. Rec. IEEE Photovolt. Spec. Conf., pp. 1601-1606, 2005.

[31] H. Zainuddin, "Module temperature modelling for free-standing photovoltaic system in equatorial climate," Ph.D. dissertation, Universiti Teknologi MARA, 2014. 